\title{
Glycated Hemoglobin as a Predictor of the Length of Hospital Stay in Patients Following Coronary Bypass Graft Surgery in the Saudi Population
}

Joud G. Almogati ${ }^{1}$; Elnazeer O. Ahmed², MD, FRCSI

DOI: $10.21470 / 1678-9741-2018-0202$

\begin{abstract}
Objective: The diabetic population has a high prevalence of coronary artery disease, and frequently patients with diabetes undergo coronary artery bypass graft (CABG) surgery. Elevated glycated hemoglobin (HbA1c) in diabetics is shown to be associated with morbidity and mortality, but the association of HbA1c with postoperative length of hospital stay (LOS) has conflicting results. In this study, we aim to identify if elevated HbA1c levels are associated with prolonged LOS after CABG surgery.

Methods: A retrospective chart review study was performed, using a total of $\mathbf{3 0 5}$ patients who were referred for CABG surgery. HbA1c levels were measured before the day of surgery. Patients were classified into two groups according to HbA1c levels: $<7 \%$
\end{abstract}

and $\geq 7 \%$. A LOS of more than 14 days was proposed as an extended LOS. HbA1c and the LOS relationship were assessed using appropriate statistical methods.

Results: Patients who had diabetes mellitus comprised $81.6 \%$ of our studied population. Sixty-four percent had HbA1c levels $\geq$ $7 \%$. There was no significant difference in the total LOS in HbA1c $<7 \%$ compared to HbA1c $\geq 7 \%$ patients $(P=0.367)$.

Conclusion: Our study results rejected the proposed hypothesis that elevated HbA1c levels $\geq 7 \%$ would be associated with prolonged hospital stay following CABG surgery in a Saudi population.

Keywords: Myocardial Revascularization. Length of Stay. Glycated Hemoglobin.

\begin{tabular}{ll}
\hline Abbreviations, acronyms \& symbols \\
\hline CABG & $=$ Coronary artery bypass graft \\
HbA1c & $=$ Hemoglobin A1c or glycated hemoglobin \\
HPLC & $=$ High pressure liquid chromatography \\
ICU & $=$ Intensive care unit \\
LOS & $=$ Length of hospital stay \\
LVEF & $=$ Left ventricular ejection fraction \\
NYHA & $=$ New York Heart Association \\
SD & $=$ Standard deviation \\
STS & $=$ Society of Thoracic Surgeons \\
\hline
\end{tabular}

\section{INTRODUCTION}

There are 425 million people with diabetes in the world, and this prevalence is estimated to reach 629 million in the year of $2045^{[1]}$. The reported prevalence of diabetes in Saudi Arabia is high, at about 30\% ${ }^{[2]}$. Overall, vascular diseases, which include

${ }^{1}$ Faculty of Medicine, King Abdulaziz University, Kingdom of Saudi Arabia.

${ }^{2}$ Cardiac Surgery Department, King Abdullah Medical City, Makkah, Kingdom of Saudi Arabia.

This study was carried out at the Cardiac Surgery Department, King Abdullah Medical City, Makkah, Kingdom of Saudi Arabia. coronary heart disease and cerebrovascular disease, account for $65 \%$ of all deaths among diabetic patients ${ }^{[3]}$, and this mortality is related to the baseline $\mathrm{HbA} 1 \mathrm{c}$ level[ ${ }^{[4-6]}$.

Plasma hemoglobin $\mathrm{Alc}(\mathrm{HbA} 1 \mathrm{c})$ reflects mean ambient fasting and postprandial glycemia over the preceding 2-3 months. It is formed by the slow irreversible, non-enzymatic glycation of valine and lysine residues in the hemoglobin molecule $e^{[7]}$.

Coronary heart disease is common in the diabetic population, and frequently patients with diabetes need coronary artery bypass graft $(C A B G)$ surgery ${ }^{[8]}$. Within the United States alone, approximately 500,000 patients undergo CABG surgery annually, of whom $20 \%$ have diabetes mellitus ${ }^{[9-11]}$. The reported incidence in Saudi Arabia of CABG in patients who have diabetes is $61.2 \%$ and $78.8 \%$ for males and females, respectively ${ }^{[12]}$.

Prevalence of high $\mathrm{HbA1c}$ is common among patients undergoing $C A B G$ surgery ${ }^{[13,14]}$, and it was found to be a risk marker for this surgery ${ }^{[15]}$. Additionally, elevated HbA1c levels preceding $C A B G$ surgery are strongly related to the severity of subsequent complications, such as in-hospital death, renal

Correspondence Address

Joud G. Almogati

(iD) http://orcid.org/0000-0001-7827-2047

King Abdulaziz University - Department Cardiac Surgery

Al-Sulaymaniyah, app258 Al-Sulaymaniyah, Jeddah 21441

Kingdom of Saudi Arabia.

E-mail: joud.almogati@gmail.com

Article received on July $17^{\text {th }}, 2018$. Article accepted on August 16 ${ }^{\text {th }}, 2018$. 
failure ${ }^{[9,16]}$, myocardial infarction, cerebrovascular accident, and deep sternal wound infection ${ }^{[16,17]}$. Hyperglycemia before surgery was found to be associated with an increased risk for complications after surgery. Additionally, controlling hyperglycemia after cardiac surgery was shown to decrease the rate of deep sternal wound infection ${ }^{[18]}$, myocardial ischemia, and other complications ${ }^{[19]}$.

Previous reports about the influence of poor long-term glycemic control on postoperative length of hospital stay (LOS) have conflicting results ${ }^{[17,20-24]}$.

Our study aims to establish if $\mathrm{HbA1c}$ levels can predict LOS in diabetic patients after CABG surgery.

\section{METHODS}

A retrospective chart review study was performed, using 315 patients who were referred for CABG surgery at King Abdullah medical city (Makkah, Saudi Arabia) from November 2013 to May 2015. Of the 315 patients, 10 patients had incomplete data, such as missing $\mathrm{HbA} 1 \mathrm{c}$ levels, and they were not included in the study. The final population consisted of 305 patients, and the cardiac surgery department database was used to retrieve patient data. The Institutional Review Board approved the study and waved the need for individual patient consent.

The clinical data included in our study were: age, sex, body mass index, New York Heart Association (NYHA) functional class, number of diseased vessels, and left ventricular ejection fraction (LVEF). The patients' history of diabetes mellitus, hypertension, dyslipidemia, history of peripheral vascular disease, and postoperative complications was also noted.

$\mathrm{HbA1c}$ levels were measured on the day of surgery or within 3 days before the operation using high pressure liquid chromatography (HPLC). Patients were classified into the following two groups based on their $\mathrm{HbA} 1 \mathrm{c}$ levels: $<7 \%$ and $\geq 7 \%$. A HbA1c level $\geq 7 \%$ was used as the threshold for uncontrolled hyperglycemia, because this level is recognized by the American Diabetes Association as representing poor diabetes contro|[25]. A LOS of more than 14 days was proposed as an extended LOS, as defined by the Society of Thoracic Surgeons (STS) ${ }^{[26]}$

\section{Statistical Analysis}

Categorized variables were presented as percentages and frequencies, while the quantitative variables are given as the mean \pm standard deviation (SD). The relationship between $\mathrm{HbA1C}$ and LOS was assessed using Pearson's Chi-square test. Clinical characteristics and morbidities were analyzed using an independent t-test and Pearson's Chi-square test where appropriate to determine the predictors of LOS. The variables were entered into a logistic regression model according to their statistical significance.

SPSS Version 16 for Windows (SPSS, Inc., Chicago, IL, USA) was used for statistical analysis. A $P$-value of $<0.05$ was assumed to represent statistical significance.

\section{RESULTS}

The clinical characteristics and preoperative data for patients are presented in Table 1. Patients who had diabetes mellitus
Table 1. Clinical characteristics of CABG patients (all patients $n=305)$.

\begin{tabular}{|c|c|c|}
\hline \multicolumn{2}{|l|}{ Clinical characteristics } & Results \\
\hline \multicolumn{2}{|l|}{ Mean age (year), (SD) } & $59.10( \pm 9.67)$ \\
\hline \multicolumn{2}{|l|}{ Male sex, n (\%) } & $250(82)$ \\
\hline \multicolumn{2}{|l|}{ Mean body mass index (kg/m²), (SD) } & $27.80( \pm 5.88)$ \\
\hline \multicolumn{2}{|l|}{ Diabetes mellitus, n (\%) } & $249(81.6)$ \\
\hline \multicolumn{2}{|l|}{ Hypertension, n (\%) } & $256(83.9)$ \\
\hline \multicolumn{2}{|l|}{ Dyslipidemia, n (\%) } & $143(46.9)$ \\
\hline \multicolumn{2}{|l|}{ History of PVD, n (\%) } & $9(3)$ \\
\hline \multirow{4}{*}{ NYHA functional class, n (\%) } & 1 & $2(0.7)$ \\
\hline & 2 & $164(53.4)$ \\
\hline & 3 & $109(35.7)$ \\
\hline & 4 & $30(9.8)$ \\
\hline \multirow{3}{*}{ Number of diseased vessels, n (\%) } & 1 & $3(1)$ \\
\hline & 2 & $32(10.5)$ \\
\hline & 3 & $270(88.5)$ \\
\hline \multicolumn{2}{|c|}{ Left ventricular ejection fraction \% mean (range) } & $43.7(15-68)$ \\
\hline \multicolumn{2}{|l|}{ Patients with $\mathrm{HbA} 1 \mathrm{c} \geq 7 \%, \mathrm{n}(\%)$} & $195(63.9)$ \\
\hline \multicolumn{2}{|l|}{ Mean $\mathrm{HbA} 1 \mathrm{c},(\mathrm{SD})$} & $8.2( \pm 2.16)$ \\
\hline \multicolumn{2}{|l|}{ Mean EuroSCORE, (SD) } & $4.3( \pm 4.25)$ \\
\hline
\end{tabular}

$\mathrm{HbA} 1 \mathrm{c}=$ glycated hemoglobin; NYHA=New York Heart Association; PVD=peripheral vascular disease; $\mathrm{SD}=$ standard deviation

comprised $81.6 \%$ (249/305) of our studied population, with a mean age 59.1 years (range, 31-87 years). The range of $\mathrm{HbA1c}$ was $4.9 \%-15 \%$, and $64 \%$ (195/305) had HbA1c levels $\geq 7 \%$. Of those patients, $96.4 \%$ (188/195) were known to have diabetes.

Complications are presented in Table 2. A total of 100 patients out of 305 (32.78\%) had postoperative complications within 30 days. The most frequent complications were atrial fibrillation (31.85\%, 97/305) and renal failure (5.2\%, 16/305). Twelve (3.93\%) patients died, and their mean EuroSCORE was 8.82 (range, 1.05 to 26.24). Twelve (3.9\%) patients developed mediastinitis, and nine

Table 2. Postoperative morbidity and mortality (all patients $n=305)$.

\begin{tabular}{l|c|c}
\hline Events & Number & Percent (\%) \\
\hline Postoperative deaths & 12 & 3.93 \\
\hline Atrial fibrillation & 97 & 31.8 \\
\hline Cerebrovascular accident & 6 & 2 \\
\hline Renal impairment & 16 & 5.2 \\
\hline Surgical site infection & 12 & 3.9 \\
\hline
\end{tabular}


of them were diabetic. Postoperative LOS ranged from 2 to 90 days (mean, $11.77 \pm 11.86$ days), with a median of 8 days. Sixtyseven percent of patients (204/305) had a LOS $\leq 10$ days, 21\% of patients (64/305) had LOS $\geq 14$ days, and only $3.6 \%$ of patients $(11 / 305)$ had $L O S \geq 40$ days.

Table 3 presents surgical outcomes related to preoperative HbA1c levels (with HbA1c <7\% compared to HbA1c $\geq 7 \%$ ). There is no correlation between increased $\mathrm{HbA1c}$ levels and 30day mortality rates, arrhythmia, cerebrovascular accident, renal failure requiring dialysis, or mediastinitis.

Table 4 presents the predictors of CABG surgery LOS, and there was no significant difference in $\mathrm{HbA} 1 \mathrm{c}<7 \%$ compared to $\mathrm{HbA} 1 \mathrm{c} \geq 7$ for total LOS using Pearson's Chi-square test $(P=0.367)$.
Using the independent t-test, LVEF\% was the only predictor of LOS to reach statistical significance $(P=0.001)$. Additionally, the logistic regression analysis for LVEF\% and LOS ( $<14$ days, $\geq 14$ days) was significant $(P \leq 0.001)$.

\section{DISCUSSION}

In this study of 305 patients, we investigated as to whether those with elevated HbA1c levels had a longer LOS compared with those with optimal HbA1c levels CABG. We found that LOS was not affected by preoperative HbA1c levels (with a cut-off point of $\mathrm{HbA} 1 \mathrm{c}=7 \%$ for optimal and suboptimal levels; $P=0.367$ ). This is in agreement with the results of previous studies that

Table 3. Comparison of postoperative morbidity and mortality with preoperative $\mathrm{HbA} 1 \mathrm{c}$ levels.

\begin{tabular}{l|c|c|c}
\hline Variables & HbA1c $<\mathbf{7 \% ( n = 1 1 0 )}$ & HbA1c $\mathbf{7 \%}(\mathbf{n = 1 9 5 )}$ & $\boldsymbol{P}$ value \\
\hline Postoperative deaths & $3(0.9 \%)$ & $12(6.2 \%)$ & 0.409 \\
\hline Arrhythmia & $30(27.3 \%)$ & $67(34.4 \%)$ & 0.202 \\
\hline Cerebrovascular accident & $1(0.9 \%)$ & $5(0.5 \%)$ & 0.600 \\
\hline Renal failure requiring dialysis & $5(4.5 \%)$ & $12(6.2 \%)$ & 0.680 \\
\hline Mediastinitis & $3(0.9 \%)$ & $9(2.9 \%)$ & 0.415 \\
\hline
\end{tabular}

Level of significance, $P<0.05$. HbA1c=glycated hemoglobin

Table 4. Predictors of length of hospital stay post coronary artery bypass graft surgery.

\begin{tabular}{|c|c|c|c|c|}
\hline \multicolumn{2}{|l|}{ Variables } & LOS $<14$ days $(n=241)$ & LOS $\geq 14$ days $(n=64)$ & $P$ value \\
\hline \multicolumn{2}{|l|}{ Age } & $59.1 \pm 9.7$ & $58.9 \pm 9.3$ & 0.856 \\
\hline \multicolumn{2}{|l|}{ Male sex } & $200(74)$ & $50(78)$ & 0.368 \\
\hline \multicolumn{2}{|l|}{ Diabetes mellitus } & $196(81.3)$ & $53(82.8)$ & 0.785 \\
\hline \multicolumn{2}{|l|}{ Hypertension } & $203(84.2)$ & $53(82.8)$ & 0.783 \\
\hline \multicolumn{2}{|l|}{ Dyslipidemia } & $111(46)$ & $32(50)$ & 0.574 \\
\hline \multicolumn{2}{|l|}{ PVD history } & $6(2.5)$ & $3(4.6)$ & 0.356 \\
\hline \multirow{4}{*}{ NYHA functional class } & 1 & $2(0.8)$ & 0 & 0.724 \\
\hline & 2 & $129(53.5)$ & $35(54.6)$ & \\
\hline & 3 & $88(36.5)$ & $21(32.8)$ & \\
\hline & 4 & $22(9.1)$ & $8(12.5)$ & \\
\hline \multirow{3}{*}{$\begin{array}{l}\text { Number of diseased } \\
\text { vessels }\end{array}$} & 1 & $3(1.2)$ & 0 & 0.665 \\
\hline & 2 & $25(10.3)$ & $7(10.9)$ & \\
\hline & 3 & $213(88.4)$ & $57(89)$ & \\
\hline \multicolumn{2}{|l|}{ LVEF \% } & $44.8 \pm 9.3$ & $39.6 \pm 9.9$ & $<0.001$ \\
\hline \multirow{2}{*}{$\mathrm{HbA1c}$} & $<7 \%$ & $90(37.3)$ & $20(31.3)$ & 0.367 \\
\hline & $\geq 7 \%$ & $151(62.6)$ & $44(68.8)$ & \\
\hline
\end{tabular}

Data are presented as the mean \pm SD or $n(\%)$

$\mathrm{HbA} 1 \mathrm{c}=$ glycated hemoglobin; LOS=Length of hospital stay; LVEF=left ventricular ejection fraction; NYHA = New York Heart

Association; PVD=peripheral vascular disease 
investigated the above relationship ${ }^{[21,22]}$. Knapik et al. ${ }^{[20]}$ reported a study in 2010 with a population of 782 diabetic patients, which showed no significant difference in total LOS (with HbA1c $\leq 7 \%$ compared to $\mathrm{HbA1c}>7 \% ; P=0.59$ ). Matsuura et al. ${ }^{[21]}$ reported similar results in a study in 2009.

Conversely, Medhi et al. ${ }^{[23]}$ conducted a study in 2001 with 135 patients, showing that HbA1c was significantly associated with postoperative LOS ( $P=0.025)$, while in a 2012 study by Najafi et al. ${ }^{[22]}$, similar results were found $(P=0.01)$. These disparities may be a result of different cut-off points to define a prolonged hospital stay (from $\geq 3$ to 7 days) ${ }^{[20,22,23]}$, different sample sizes, and different study populations.

Postoperative LOS ranged from 2 to 90 days (mean, $11.77 \pm$ 11.86 days) with a median of 8 days. This is longer than the postCABG LOS that was reported by others ${ }^{[22,23]}$.

We found that the LVEF can predict LOS following CABG $(P=0.001)$. Najafi et al. ${ }^{[22]}$ reported that LVEF was not a significant predictor of LOS, but their findings were only for intensive care unit (ICU) LOS, and not for the overall length of hospital stay. The most common complication was atrial fibrillation, which was observed in about 32\% of patients. This is similar to results reported in previous studies ${ }^{[22,23]}$. There was no significant difference in the post-operative complication rate between $\mathrm{HbA} 1 \mathrm{c}<7 \%$ and $\mathrm{HbA} 1 \mathrm{c} \geq 7 \%$. A study in 2017 by Finger et al. ${ }^{[17]}$ showed similar results, except that sternal wound infections were significantly increased in the $\mathrm{HbA1c} \geq 7 \%$ group $(P=0.030)$.

In diabetics scheduled for CABG, poor preoperative glycemic control (suggested by $\mathrm{HbA1c}$ ) is common, and $64 \%$ of our population had $\mathrm{HbA} 1 \mathrm{c} \geq 7 \%$.

To our knowledge, this study is the first to present data on the prevalence of elevated $\mathrm{HbA} 1 \mathrm{c}$ in patients undergoing $\mathrm{CABG}$, and its relation to LOS in Saudi Arabia.

The limitations of this study were that it was conducted at one health center, which may limit its generalizability, and its retrospective nature; not all the information was available as a result of poor documentation because the data was recorded in the past. However, there was a sufficiently large sample size for our purposes.

\section{CONCLUSION}

Our study results rejected the proposed hypothesis that elevated $\mathrm{HbA} 1 \mathrm{c}$ levels $>7 \%$ would be associated with a prolonged hospital stay following CABG surgery in a Saudi population.

\section{Authors' roles $\&$ responsibilities}

JGA Contributions to the design, acquisition, interpretation of data and drafting the work; final approval of the version to be published

EOA Contributions to the design, acquisition, interpretation of data and drafting the work; final approval of the version to be published

\section{REFERENCES}

1. International Diabetes Federation 2017. International diabetes atlas. 8th ed. [cited 2018 June 12]. Available from: http://www.diabetesatlas.org/ across-the-globe.html.

2. Alqurashi KA, Aljabri KS, Bokhari SA. Prevalence of diabetes mellitus in a Saudi community. Ann Saudi Med. 2011;31(1):19-23.

3. Geiss LS, Herman WH, Smith PJ, National Diabetes Data Group. Diabetes in America. Bethesda: National Institutes of Health, National Institute of Diabetes and Digestive and Kidney Diseases; 1995. p.233-57.

4. Xu L, Chan WM, Hui YF, Lam TH. Association between HbA1c and cardiovascular disease mortality in older Hong Kong Chinese with diabetes. Diabet Med. 2012;29(3):393-8.

5. Turner RC, Millns H, Neil HA, Stratton IM, Manley SE, Mathews DR, et al. Risk factors for coronary artery disease in non-insulin dependent diabetes mellitus: United Kingdom Prospective Diabetes Study (UKPDS:23). BMJ. 1998;316(7134):823-8.

6. Saydah S, Tao M, Imperatore G, Gregg E. GHb level and subsequent mortality among adults in the U.S. Diabetes Care. 2009;32(8):1440-6.

7. Krishnamurti U, Steffes MW. Glycohemoglobin: a primary predictor of the development or reversal of complications of diabetes mellitus. Clin Chem. 2001;47(7):1157-65.

8. Skyler JS. Relationship of glycemic control to diabetic complication. In: Porte DJ, Sherwin RS, eds. Ellenberg \& Rifkin's diabetes mellitus. Stamford: Appleton and Lange; 1996. p.1235-54.

9. Halkos ME, Puskas JD, Lattouf OM, Kilgo P, Kerendi F, Song HK, et al. Elevated preoperative hemoglobin A1c level is predictive of adverse events after coronary artery bypass surgery. J Thorac Cardiovasc Surg. 2008;136(3):631-40.

10. Halkos ME, Lattouf OM, Puskas JD, Kilgo P, Cooper WA, Morris CD, et al. Elevated preoperative hemoglobin A1c level is associated with reduced long-term survival after coronary artery bypass surgery. Ann Thorac Surg. 2008;86(5):1431-7.

11. Estrada CA, Young JA, Nifong LW, Chitwood WR Jr. Outcomes and perioperative hyperglycemia in patients with or without diabetes mellitus undergoing coronary artery bypass grafting. Ann Thorac Surg. 2003;75(5):1392-9.

12. Ahmad M, Arifi AA, Onselen Rv, Alkodami AA, Zaibag M, Khaldi AA, et al. Gender differences in the surgical management and early clinical outcome of coronary artery disease: single centre experience. J Saudi Heart Assoc. 2010;22(2):47-53.

13. Engoren M, Habib RH, Zacharias A, Schwann TA, Riordan CJ, Durham SJ, et al. The prevalence of elevated hemoglobin A1 $\mathrm{c}$ in patients undergoing coronary artery bypass surgery. J Cardiothorac Surg. 2008;3:63.

14. Alserius T, Anderson RE, Hammar N, Nordqvist T, Ivert T. Elevated glycosylated haemoglobin ( $\mathrm{HbA1c}$ ) is a risk marker in coronary artery bypass surgery. Scand Cardiovasc J. 2008;42(6):392-8.

15. Alserius T, Hammar N, Nordqvist T, Ivert T. Improved survival after coronary artery bypass grafting has not influenced the mortality disadvantage in patients with diabetes mellitus. J Thorac Cardiovasc Surg. 2009;138(5):1115-22.

16. Hudson C, Welsby I, Phillps-Bute B, Mathew JP, Lutz A, Chad Hughes G, et al; Cardiothoracic Anesthesiology Research Endeavors (C.A.R.E.) Group. Glycosylated hemoglobin levels and outcome in non-diabetic cardiac surgery patients. Can J Anesth. 2010;57(6):565-72.

17. Finger B, Brase J, He J, Gibson WJ, Wirtz K, Flynn BC. Elevated hemoglobin $\mathrm{A} 1 \mathrm{C}$ is associated with lower socioeconomic position and increased postoperative infections and longer hospital stay after cardiac surgical procedures. Ann Thorac Surg. 2017;103(1):145-51.

18. Zerr KJ, Furnary AP, Grunkemeier GL, Bookin S, KanhereV, Starr A. Glucose control lowers the risk of wound infection in diabetics after open heart operations. Ann Thorac Surg. 1997;63(2):356-61. 
19. Lazar HL, Chipkin SR, Fitzgerald CA, Bao Y, Cabral H, Apstein CS. Tight glycemic control in diabetic coronary artery bypass graft patients improves perioperative outcomes and decreases recurrent ischemic events. Circulation. 2004;109(12):1497-502.

20. Knapik P, Ciesla D, Filipiak K, Knapik M, Zembala M. Prevalence and clinical significance of elevated preoperative glycosylated hemoglobin in diabetic patients scheduled for coronary artery surgery. Eur J Cardiothorac Surg. 2011;39(4):484-9.

21. Matsuura K, Imamaki M, Ishida A, Shimura H, Niitsuma Y, Miyazaki M. Off-pump coronary artery bypass grafting for poorly controlled diabetic patients. Ann Thorac Cardiovasc Surg. 2009;15(1):18-22.

22. Najafi M, Goodarzynejad H. Determinants of length of stay in surgical ward after coronary bypass surgery: glycosylated hemoglobin as a predictor in all patients, diabetic or non-diabetic. JTehran Heart Cent. 2012;7(4):170-6. 23. Medhi M, Marshall MC Jr, Burke HB, Hasan R, Nayak D, Reed G, et al. $\mathrm{HbA1}$ c predicts length of stay in patients admitted for coronary artery bypass surgery. Heart Dis. 2001;3(2):77-9.

24. Omar AS, Salama A, Allam M, Elgohary Y, Mohammed S, Tuli AK, et al. Association of time in blood glucose range with outcomes following cardiac surgery. BMC Anesthesiol. 2015;15:14.

25. ADA Diabetes Guidelines Glycemic Targets A1C | NDEl. (2017). [online] Ndei.org. [cited 2018 June 12] Available from: http://www.ndei.org/ ADA-diabetes-management-guidelines-glycemic-targets-A1C-PG.aspx .

26. Society of Thoracic Surgeons. Quality performance measures [cited 2018 June 12] Available from: http://www.sts.org/quality-research-patientsafety/quality/quality-performance-measures 